\title{
The HDAC6/8/10 inhibitor TH34 induces DNA damage-mediated cell death in human high-grade neuroblastoma cell lines
}

\author{
Fiona R. Kolbinger ${ }^{1,2} \cdot$ Emily Koeneke ${ }^{1,2,3}$. Johannes Ridinger ${ }^{1,2,3} \cdot$ Tino Heimburg $^{4} \cdot$ Michael Müller $^{1,2}$. \\ Theresa Bayer ${ }^{4}$. Wolfgang Sippl ${ }^{4} \cdot$ Manfred Jung $^{5} \cdot$ Nikolas Gunkel $^{6} \cdot$ Aubry K. Miller $^{6} \cdot$ Frank Westermann $^{7}$. \\ Olaf Witt ${ }^{1,2,8} \cdot$ Ina Oehme ${ }^{1,2}$
}

Received: 22 February 2018 / Accepted: 4 June 2018 / Published online: 9 June 2018

(c) The Author(s) 2018

\begin{abstract}
High histone deacetylase (HDAC) 8 and HDAC10 expression levels have been identified as predictors of exceptionally poor outcomes in neuroblastoma, the most common extracranial solid tumor in childhood. HDAC8 inhibition synergizes with retinoic acid treatment to induce neuroblast maturation in vitro and to inhibit neuroblastoma xenograft growth in vivo. HDAC10 inhibition increases intracellular accumulation of chemotherapeutics through interference with lysosomal homeostasis, ultimately leading to cell death in cultured neuroblastoma cells. So far, no HDAC inhibitor covering HDAC8 and HDAC10 at micromolar concentrations without inhibiting HDACs 1, 2 and 3 has been described. Here, we introduce TH34 (3-( $N$-benzylamino)-4-methylbenzhydroxamic acid), a novel HDAC6/8/10 inhibitor for neuroblastoma therapy. TH34 is welltolerated by non-transformed human skin fibroblasts at concentrations up to $25 \mu \mathrm{M}$ and modestly impairs colony growth in medulloblastoma cell lines, but specifically induces caspase-dependent programmed cell death in a concentration-dependent manner in several human neuroblastoma cell lines. In addition to the induction of DNA double-strand breaks, HDAC6/8/10 inhibition also leads to mitotic aberrations and cell-cycle arrest. Neuroblastoma cells display elevated levels of neuronal differentiation markers, mirrored by formation of neurite-like outgrowths under maintained TH34 treatment. Eventually, after long-term treatment, all neuroblastoma cells undergo cell death. The combination of TH34 with plasma-achievable concentrations of retinoic acid, a drug applied in neuroblastoma therapy, synergistically inhibits colony growth (combination index (CI) $<0.1$ for $10 \mu \mathrm{M}$ of each). In summary, our study supports using selective HDAC inhibitors as targeted antineoplastic agents and underlines the therapeutic potential of selective HDAC6/8/10 inhibition in high-grade neuroblastoma.
\end{abstract}

Keywords Selective histone deacetylase inhibitor $\cdot$ HDAC8 $\cdot$ HDAC10 $\cdot$ DNA repair - Differentiation - Targeted therapy

Electronic supplementary material The online version of this article (https://doi.org/10.1007/s00204-018-2234-8) contains supplementary material, which is available to authorized users.

Ina Oehme

i.oehme@kitz-heidelberg.de

1 Preclinical Program, Hopp Children's Cancer Center at NCT Heidelberg (KiTZ), 69120 Heidelberg, Germany

2 Clinical Cooperation Unit Pediatric Oncology, German Cancer Research Center (DKFZ), and German Cancer Consortium (DKTK), Im Neuenheimer Feld 280, 69120 Heidelberg, Germany

3 Faculty of Biosciences, Heidelberg University, Im Neuenheimer Feld 234, 69120 Heidelberg, Germany

4 Department of Medicinal Chemistry, Institute of Pharmacy, Martin-Luther-University Halle-Wittenberg, W.-Langenbeck-Str. 4, 06120 Halle, Germany
5 Institute of Pharmaceutical Sciences, Albert-Ludwigs-Universität Freiburg, Albertstraße 25, 79104 Freiburg, Germany

6 Cancer Drug Development Group, German Cancer Research Center (DKFZ), Im Neuenheimer Feld 580, 69120 Heidelberg, Germany

7 Research Group Neuroblastoma Genomics, German Cancer Research Center (DKFZ), Im Neuenheimer Feld 280, 69120 Heidelberg, Germany

8 Department of Pediatric Oncology, Hematology and Immunology, University Hospital Heidelberg, Im Neuenheimer Feld 430, 69120 Heidelberg, Germany 


\section{Introduction}

Neuroblastoma is the most common extracranial solid tumor in childhood and the most frequently occurring cancer in infancy, accounting for $15 \%$ of pediatric cancer mortality (Brodeur 2003; Ward et al. 2014). Its clinical presentation is diverse, including highly differentiated local tumors with an excellent prognosis, spontaneously regressing metastatic disease and chemotherapy-resistant, invasive masses, which are likely to relapse. Treatment regimens for high-risk tumors involve dose-intensive chemotherapy, surgical resection and a combination of immunotherapy, antibodies and 13-cis retinoic acid (Cheung and Dyer 2013; Pinto et al. 2015; PDQ Pediatric Treatment Editorial Board, PDQ Cancer Information Summaries [Internet]. Bethesda (MD): National Cancer Institute (US) 2002-2017). Despite high-intensity chemotherapy, overall survival in high-risk neuroblastoma remains poor and chemotherapy-related toxicities are commonly observed. Thus, research has recently focused on the identification of novel, druggable targets and developing respective antineoplastic agents to abolish therapy resistance mechanisms and minimize chemotherapy-related adverse events.

The classical histone deacetylase (HDAC) family comprises 11 enzymatic subtypes, which, according to evolutionarily preserved catalytic domains, are divided into classes I (HDACs 1, 2, 3 and 8), IIa (HDACs 4, 5, 7 and 9), IIb (HDACs 6 and 10) and IV (HDAC11). Since HDACs catalyze the removal of acetyl groups from lysine residues of nuclear as well as cytoplasmic substrates, they affect diverse cellular processes including cell cycle control, apoptosis, metabolic homeostasis, stress response and autophagy (de Ruijter et al. 2003; Kim et al. 2001; Li and Zhu 2014; Yang and Seto 2008). Moreover, HDAC functions are protective against DNA damage, and depletion or inhibition of HDACs impair DNA damage repair mechanisms, rendering cells more susceptible to DNA-damaging agents (Miller et al. 2010). Recent evidence illustrates that HDAC inhibitors themselves propel DNA damage through replicative stress and a reduction of DNA repair proteins (Nikolova et al. 2017). HDACs are validated targets in anti-tumoral therapy and, to date, five HDAC inhibitors (panobinostat, romidepsin, belinostat, vorinostat and chidamide) have been approved for the treatment of hematological malignancies (Bates et al. 2015; Cheng et al. 2015; Mann et al. 2007; O'Connor et al. 2015; Shi et al. 2015). The approved HDAC inhibitors target multiple HDACs, including HDACs 1, 2 and 3, which are associated with serious, dose limiting adverse effects including leukopenia, thrombocytopenia, anorexia, vomiting, diarrhea and fatigue, mainly ascribed to an inhibition of HDACs 1 ,
2 and 3 (Bradner et al. 2010; Lane and Chabner 2009; Oehme et al. 2009a; Witt et al. 2009b). Selective targeting of tumor-relevant HDAC subtypes while avoiding inhibition of HDACs 1, 2 and 3 may thus lead to an increased therapeutic window with limited toxicity to healthy tissue (Balasubramanian et al. 2009).

HDAC8 is the only HDAC that is significantly transcriptionally upregulated in high-grade (INSS stage 4) neuroblastoma patient samples as compared to prognostically favorable stage 1, 2, 3 and 4S tumors. High HDAC8 expression strongly correlates with markers of poor prognosis (Oehme et al. 2009b). Selective HDAC8 inhibition induces a differentiated phenotype in neuroblastoma and reduces neuroblastoma growth in vitro and in vivo at least as effectively as unspecific HDAC inhibition while displaying fewer adverse effects (Rettig et al. 2015). This endorses selective HDAC8 inhibition as a very promising therapeutic option in neuroblastoma.

Class IIb HDACs 6 and 10 play an important role in protein degradation, lysosomal trafficking and cellular stress response (Kawaguchi et al. 2003; Koeneke et al. 2015; Kramer et al. 2014; Park et al. 2008; Yang and Seto 2008). HDAC10 expression strongly correlates with poor overall survival in high-grade (INSS stage 4) neuroblastoma (Oehme et al. 2013), making this HDAC a particularly attractive druggable target in this entity. HDAC10 supports neuroblastoma cell survival by promoting autophagic flux, and inhibition of HDAC10 sensitizes chemotherapy-resistant cells to treatment with DNA damage-inducing drugs such as doxorubicin (Oehme et al. 2013). In addition, HDAC10 promotes DNA damage repair (Radhakrishnan et al. 2015). HDAC6 expression does not significantly correlate with prognostic markers in neuroblastoma (Oehme et al. 2009b). HDAC6 and 10 share highly-conserved catalytic domains (Fischer et al. 2002) and structurally, it is therefore, utterly challenging to strictly avoid inhibition of one class IIb HDAC while significantly impairing the other subtype's function. Inhibition of HDAC6 has been found to be well tolerated in preclinical and clinical studies (Santo et al. 2012; Vogl et al. 2017; Yee et al. 2016), which is why inhibition of HDAC6 did not lead to exclusion of a candidate inhibitor in this study.

Here, we present the novel small-molecule HDAC inhibitor TH34, which is the first HDAC inhibitor that shows pronounced selectivity for HDACs 6,8 and 10 over HDACs 1, 2 and 3. Consistent with previous findings, treatment of neuroblastoma cells with TH34 induces signs of neuronal differentiation. Furthermore, we characterize DNA damage-inducing and cytotoxic effects of TH34 treatment in neuroblastoma, and identify the combination of the novel HDAC inhibitor with retinoic acid as synergistic and very effective in specifically eliminating tumor cells but not non-malignant fibroblasts. Taken together, 
our findings underline the specific roles of HDACs 8 and 10 in high-grade neuroblastoma and provide a rationale for further development of TH34 and all-trans retinoic acid (ATRA) as a treatment combination in this pediatric cancer entity.

\section{Materials and methods}

\section{Cell culture}

Human neuroblastoma cell lines SK-N-BE(2)-C (European Collection of Authenticated Cell Cultures, ECACC, Salisbury, UK), IMR-32 (German Collection of Microorganisms and Cell Cultures, DSMZ, Darmstadt, Germany), SK-N-AS (kindly provided by M. Schwab, DKFZ) and SH-SY5Y (DSMZ) as well as human medulloblastoma cell line MED8A (kindly provided by R. Gilbertson, St Jude Children's Research Hospital, Memphis, TN, USA) and the non-transformed human foreskin fibroblast cell line VH7 (kindly provided by P. Boukamp, DKFZ) were cultured in Dulbecco's Modified Eagle Medium (DMEM, Lonza, Basel, Switzerland) supplemented with $10 \%$ fetal calf serum (FCS, Sigma-Aldrich, Munich, Germany) and 1\% non-essential amino acids (NEAA, Lonza). Kelly (DSMZ) and HD-MB03 (kindly provided by T. Milde, DKFZ) cells were cultured in RPMI 1640 medium (ThermoFisher Scientific, Braunschweig, Germany) containing $10 \%$ FCS and $1 \%$ NEAA. All cell lines were routinely authenticated using DNA fingerprinting authentication (DSMZ) and screened for mycoplasma contamination (Multiplexion, Heidelberg, Germany). All cell lines were cultured under standard conditions at $37{ }^{\circ} \mathrm{C}$ in a humidified atmosphere containing $5 \%$ $\mathrm{CO}_{2}$ and passages 15-30 were used.

\section{Primary neuroblastoma culture}

Collection and use of neuroblastoma specimens was approved by the Institutional Review Board of the Medical Faculty, University of Heidelberg, and informed consent was obtained by the patient's guardians. Bone marrow aspirates with high tumor cell infiltration were used to establish a primary culture. Briefly, neuroblastoma cells were isolated using a Ficoll gradient separation and subsequently cultured on matrigel-coated cell culture dishes in RPMI-1640 + 10\% FCS for 7 days. Neuroblastoma spheroids were then sub-cultured for 2-3 passages before freezing in 10\% DMSO + 20\% FCS.

\section{Cell culture reagents and chemicals}

TH34 (3-( $N$-benzylamino)-4-methylbenzhydroxamic acid) (stock concentration $50 \mathrm{mM}$ ) was synthesized by coauthors
TH and WS as described previously (Heimburg et al. 2016, 2017) and was dissolved in DMSO (Sigma-Aldrich). Alltrans retinoic acid (ATRA, Sigma-Aldrich, stock concentration $10 \mathrm{mM}$ ) was dissolved in ethanol (EtOH, SigmaAldrich). Z-VAD-FMK (Biozol, Eching, Germany, stock concentration $100 \mathrm{mM}$ ), necrostatin-1 (Cayman Chemical, Tallinn, Estonia, stock concentration $50 \mathrm{mM}$ ) and trolox (kindly provided by N. Brady, Johns Hopkins Bloomberg School of Public Health, Baltimore, MD, USA, stock concentration $50 \mathrm{mM}$ ) were dissolved in DMSO. $N$-Acetylcysteine (NAC, Sigma-Aldrich, stock concentration $1 \mathrm{mM}$ ) was dissolved in autoclaved Millipore $\mathrm{H}_{2} \mathrm{O}$ and stored at $4{ }^{\circ} \mathrm{C}$ protected from light. If not otherwise specified, compounds were stored at $-20^{\circ} \mathrm{C}$ and protected from light.

\section{NanoBRET assay}

HeLa cells, stably transfected with NanoBRET plasmids NanoLuc ${ }^{\circledR}$-HDAC6 FL Fusion Vector and NanoLuc ${ }^{\circledR}{ }_{-}$HDAC10 FL Fusion Vector (Promega, Madison, WI, USA) were seeded at 20,000 cells/well in white 96-well plates. Without further incubation, tracer $(0.3 \mu \mathrm{M})$ and drugs were added in separate steps and plates were placed in a tissue culture incubator for $2 \mathrm{~h}$. For NanoBRET quantification, plates were put at room temperature for $10 \mathrm{~min}$. Nanoglow substrate, diluted in OptiMEM without phenol red, was added and measured within $10 \mathrm{~min}$ in an OPTIMA plate reader $(460 \mathrm{~nm}$ emission for donor and 610LP filter for acceptor, BMG Labtech, Ortenberg, Germany). The BRET signal was calculated by the ratio of acceptor signal to donor signal.

\section{Western blot analysis}

Western blot analysis was performed as described previously described (Oehme et al. 2009b). The following antibodies were used: anti-histone 3 (\#9715, Cell Signaling Technology, Leiden, The Netherlands), anti-acetylated histone 3 (\#06-911, Millipore), anti-tubulin (\#2148, Cell Signaling Technology), anti-acetylated tubulin (\#6793, Sigma-Aldrich), anti-acetylated SMC3 (kindly provided by Katsuhiko Shirahige, Institute for Molecular and Cellular Biosciences, University of Tokyo, Japan (Nishiyama et al. 2010)), anti-HSC70/HSP70 (\#sc-33575, Santa Cruz Biotechnology, Heidelberg, Germany), and anti- $\beta$-actin (\#5441, Sigma-Aldrich).

\section{Acridine orange staining}

Acridine orange-positive acidic vesicular organelles were detected as previously described (Oehme et al. 2013). 


\section{Determination of biochemical HDAC3 activity}

Ten doses of TH34 were tested by the company Reaction Biology Corp. (Malvern, PA, USA) against a specific fluorogenic HDAC3 substrate (peptide RHKK(Ac)AMC from $\mathrm{p} 53$ residues 379-382) in three-fold serial dilution, starting at $1000 \mu \mathrm{M}$. Trichostatin A (threefold serial dilution starting at $10 \mu \mathrm{M}$ ) served as a positive control and IC50 values were calculated using GraphPad Prism version 5.01 (GraphPad Software).

\section{Class Ila HDAC activity assay}

Class IIa HDAC activity was performed as previously described (Ecker et al. 2015).

\section{Cell viability analysis}

Adherent cells were detached using trypsin-EDTA (ThermoFisher Scientific) and pooled with corresponding supernatant, centrifuged and resuspended in $1 \mathrm{ml}$ of cell culture medium. Cell viability was measured by automated trypan blue staining using the Vi-Cell XR Cell Viability Analyzer (Beckman Coulter, Krefeld, Germany). Caspase-3-like protease activity was analyzed as previously described (Oehme et al. 2009b).

\section{Cell cycle analysis}

Cell cycle analysis was performed as previously described (Oehme et al. 2006).

\section{Histone protein H2AX phosphorylation assay ( $p \mathrm{H} 2 \mathrm{AX})$}

Phosphorylation of histone protein $\mathrm{H} 2 \mathrm{AX}$ on serine 139 indicates DNA double-strand breaks and blockage of replication forks (Mariotti et al. 2013; Muslimovic et al. 2008). After treatment as indicated, $4 \times 10^{5}$ viable cells were transferred to a round-bottom plate. Cells were fixed and permeabilized using buffers using the eBioscience ${ }^{\mathrm{TM}}$ Foxp3/Transcription Factor Staining Buffer Set (ThermoFisher Scientific) according to manufacturer's protocol. Subsequently, cells were incubated for $1.5 \mathrm{~h}$ with $\gamma \mathrm{H} 2 \mathrm{AX}$ primary antibody (ThermoFisher Scientific) on ice, washed twice and incubated with anti-rabbit Alexa Fluor ${ }^{\circledR} 488$ secondary antibody for $1 \mathrm{~h}$ on ice before washing and measurement utilizing a FACSCanto II Flow Cytometer (Becton, Dickinson and Company).

\section{Fluorescence microscopic analysis of NEFM and $\mathrm{\gamma H} 2 \mathrm{AX}$ staining}

SK-N-BE(2)-C cells were seeded at a density of $2 \times 10^{4}$ cells per well into an ibidi 8 -well $\mu$-slide and treated for $24 \mathrm{~h}$ as indicated. Adherent cells were washed with PBS, fixed for 15 min using 4\% paraformaldehyde (PFA) at room temperature, permeabilized for $30 \mathrm{~min}$ with $0.2 \%$ TritonX 100 (ThermoFisher Scientific) in phosphate-buffered saline (PBS) and blocked with 3\% BSA in $0.05 \%$ Triton-X 100 (ThermoFisher Scientific) in PBS for $1 \mathrm{~h}$ at room temperature. Primary antibodies were diluted 1:500 (NEFM, Millipore) or 1:200 ( $\gamma \mathrm{H} 2 \mathrm{AX}$, Cell Signaling Technology) and after overnight incubation, cells were incubated with fluorescent secondary antibody for $2 \mathrm{~h}$ at room temperature and counterstained with DAPI. Images were acquired on a CKX41 light microscope (Olympus, Hamburg, Germany) with a reflected fluorescence system or a Zeiss LSM710 laser scanning confocal microscope (Carl Zeiss, Oberkochen, Germany).

\section{Quantitative real-time PCR}

Real-time PCR was performed as described previously (Fischer et al. 2005; Witt et al. 2003). Unless otherwise indicated, primers were purchased from ThermoFisher Scientific, and the following primers were used: $C D K N 1 A$ (p21 ${ }^{\mathrm{WAF} 1 / \mathrm{CIP} 1}$, forward: 5'-TGGAGACTCTCAGGGTCG AAA-3', reverse: 5'-GGCGTTTGGAGTGGTAGAAATC3'), HPRT (forward: 5'-TGACACTGGCAAAACAAT GCA-3', reverse: 5'-GGTCCTTTTCACCAGCAAGCT-3'), NTRK1 (forward: 5'-CAGCCGGCACCGTCTCT-3', reverse: 5'-TCCAGGAACTCAGTGAAGATGAAG-3'), PUMA (forward: 5'-CCTGGAGGGTCCTGTACAATCT-3', reverse: 5'-GCACCTAATTGGGCTCCATCT-3'), SDHA (forward: 5'-TGGGAACAAGAGGGCATCTG-3', reverse: 5'-CCA CCACTGCATCAAATTCATG-3'). Data are expressed as relative gene expression (fold change) according to the $2^{-\Delta \Delta \mathrm{Ct}}$ method (Livak and Schmittgen 2001), normalized to neuroblastoma housekeeping genes SDHA and HPRT (Fischer et al. 2005) and set in relation to negative control.

\section{Cell differentiation assay}

Adherent cells plated on 6-well plates were treated as indicated. For staining, cells were rinsed once with (PBS) and incubated with crystal violet staining solution $(1 \%(\mathrm{w} / \mathrm{v})$ in $70 \% \mathrm{EtOH}$ ) for $1 \mathrm{~min}$. Subsequently, the staining solution was removed and cells were rinsed two to three times with autoclaved purified water and allowed to dry. A semi-automated macro determining surface of cell bodies as well as number and length of neurites was used for evaluation of ten fields of vision in ImageJ version $1.49 \mathrm{v}$ and normalized to solvent control.

\section{Colony formation assay}

Cells were plated on 6-well plates at a density of 500 (SKN-BE(2)-C), 750 (MED8A) or 1,000 (IMR-32, Kelly, 
SH-SY5Y, SK-N-AS, HD-MB03) cells per well and treated as indicated for $96 \mathrm{~h}$. Adherent cells were washed three times with PBS and cultured for 7 additional days before staining of viable cell colonies with crystal violet and quantification using ImageJ version 1.49v (Schneider et al. 2012). For synergism calculation, combination indices were determined from quantified colony growth using the CompuSyn synergism calculation software based on the Chou-Talalay method (Chou 2010).

\section{CellTiter-Glo assay}

Cells were plated on 96-well plates at a density of 10,000 (SK-N-BE(2)-C, IMR-32, Kelly) or 20,000 (NB8) cells per well and treated as indicated for $72 \mathrm{~h}$. According to manufacturer's protocol, cells were incubated with reagent for $25 \mathrm{~min}$ using the CellTiter-Glo 2.0 kit (Promega, SK-N-BE(2)-C, IMR-32, Kelly) or the CellTiter-Glo 3D kit (Promega, NB8) and bioluminescence was read in an OPTIMA plate reader (BMG Labtech).

\section{Statistical analysis}

Data are presented as mean \pm standard deviation (SD). All cell culture experiments were performed in duplicate or triplicate, and each experiment was repeated at least three times. A two-tailed unpaired $t$ test was performed using GraphPad Prism version 5.01 (GraphPad Software) to compare treatment groups, and p values of less than 0.05 were considered to be significant $(* p<0.05, * * p<0.01, * * * p<0.001)$.

\section{Results}

\section{The HDAC inhibitor TH34 selectively inhibits HDACs 6, 8 and 10}

As no such compound has been developed to date, we sought to develop a novel HDAC inhibitor with high selectivity for HDAC8 and HDAC10 over HDACs 1, 2 and 3, and tolerated HDAC6 inhibition during the screening process (Fig. 1a, b). Following computer-based screening of an in-house library of hydroxamic acids, inhibitors displaying promising effects in cell-free biochemical assays were tested for specificity and anti-tumor effects in multiple pediatric cancer cell lines, including high-grade neuroblastoma cells (Heimburg et al. 2017). Fluorometric determination of biochemical HDAC inhibition displayed no substantial effect against HDACs 1, 3 (Supplementary Table, Supplementary Fig. 1a, (Heimburg et al. 2017)) as well as class IIa HDACs (Supplementary Table, Supplementary Fig. 1b, c). Measurement of cellular target engagement with a NanoBRET assay (Robers et al. 2015) revealed that candidate inhibitor TH34 (Fig. 1a, b) strongly binds HDAC6, 8 and 10 with low-micromolar IC $_{50}$ concentrations (HDAC6: $4.6 \mu \mathrm{M}$, HDAC8: $1.9 \mu \mathrm{M}$, HDAC10: $7.7 \mu \mathrm{M}$ ), and shows no substantial affinity to HDAC2 at concentrations up to $50 \mu \mathrm{M}$ (Fig. 1c). Analysis of intracellular substrate acetylation in SK-N-BE(2)-C high-grade neuroblastoma cells confirmed these findings. Whereas acetylation of the specific HDAC8 target structural maintenance of chromosomes protein 3 (SMC3, Fig. 1d) and the HDAC6 target tubulin (Fig. 1e) significantly increased after 6 h of treatment with TH34, histone 3 (H3) acetylation status remained unchanged (Fig. 1f), indicating no effect on HDACs 1, 2 and 3. Moreover, treatment of SK-N-BE(2)$\mathrm{C}$ cells with TH34 induced strong accumulation of acidic vesicles, quantified via flow-cytometric analysis using the acidophilic dye acridine orange (Fig. $1 \mathrm{~g}$ ). This cellular phenotype is observed after specific knockdown or inhibition of HDAC10 (Oehme et al. 2013) and was used as a method to further support intracellular HDAC10 inhibition.

\section{TH34 induces caspase-dependent programmed cell death in neuroblastoma cells}

To investigate the long-term effect of a simultaneous inhibition of HDAC6, 8 and 10 on pediatric cancer cell lines, we treated five neuroblastoma and two medulloblastoma cell lines, featuring different genetic aberrations, with TH34 for 4 days and allowed remaining cells to regrow colonies in fresh media for another 7 days. TH34 treatment abolished colony growth in neuroblastoma cells independent of their genetic status, whereas the effect was not as pronounced in medulloblastoma cell lines (Fig. 2a, b).

To characterize tumor cell death induced by combined inhibition of HDAC6, 8 and 10, we quantified the fraction of cells in subG1 cell cycle phase after $72 \mathrm{~h}$ of TH34 treatment. TH34 significantly increased the subG1 fraction of SK-N-BE(2)-C cells in a dose-dependent manner (Fig. 2c). We then treated and co-incubated cells with TH34 and the pan-caspase inhibitor Z-VAD-FMK. TH34 activated effector caspases and cell death in SK-N-BE(2)-C high-grade neuroblastoma cells in a concentration-dependent manner, which could be rescued by addition of Z-VAD-FMK (Fig. 2d-f). At the same time, TH34-induced cell death could not be significantly rescued by addition of potent inhibitors of ROS-dependent cell death ( $N$-acetylcysteine, NAC, Supplementary Fig. 2a), necroptosis (necrostatin-1, Supplementary Fig. 2b) and oxidative stress-induced cell death (trolox, Supplementary Fig. 2c). Furthermore, expression of pro-apoptotic p53 upregulated modulator of apoptosis (PUMA) was significantly increased in IMR-32 (TP53 wild-type) cells following $72 \mathrm{~h}$ of TH34 treatment (Fig. $2 \mathrm{~g}$ ). In TP53-mutated SK-N-BE(2)-C cells, PUMA expression could not be detected. 
a<smiles>Cc1ccc(C(=O)NO)cc1NCc1ccccc1</smiles>

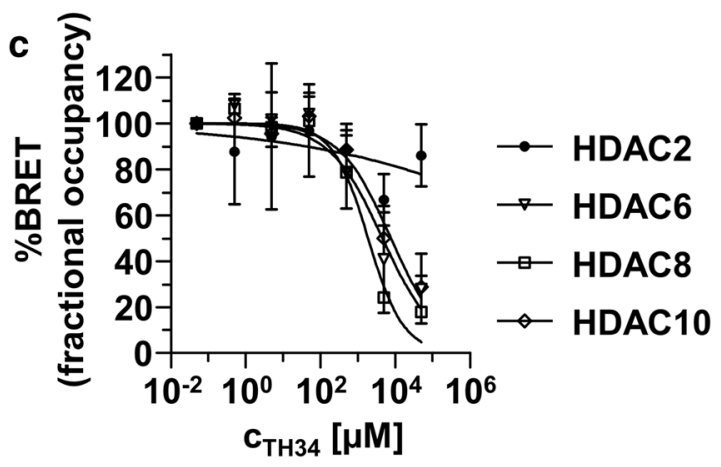

d
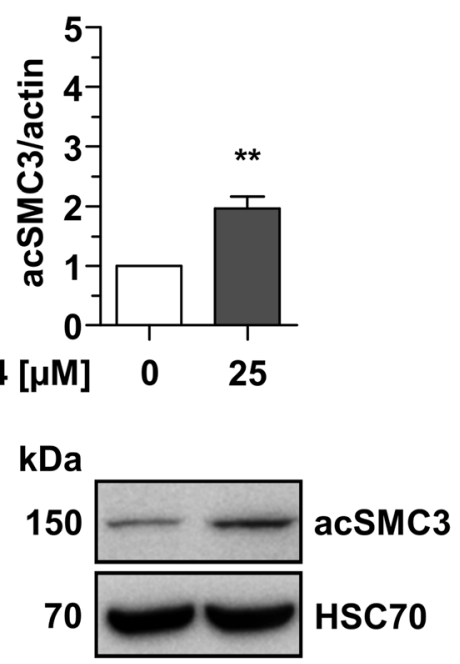

b

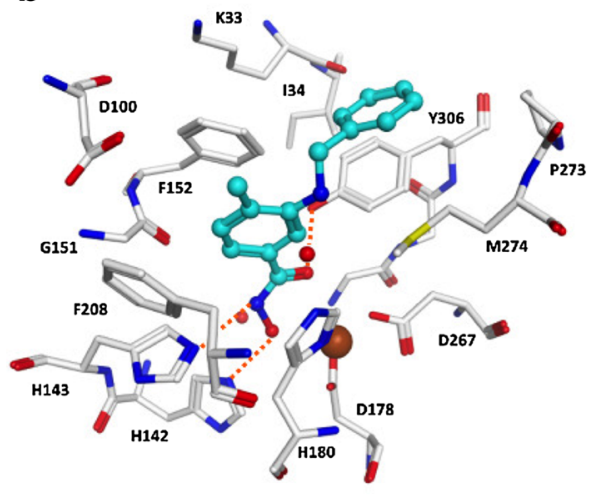

e
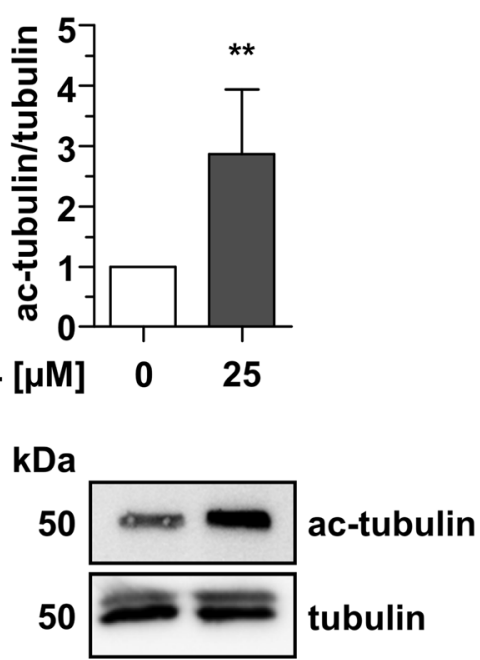
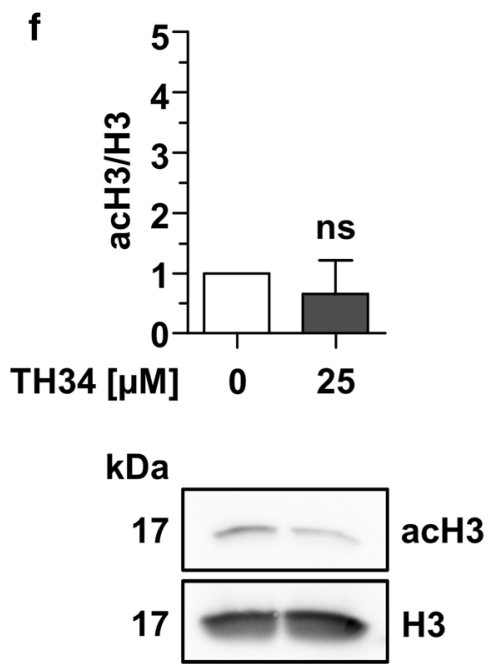

\section{g}

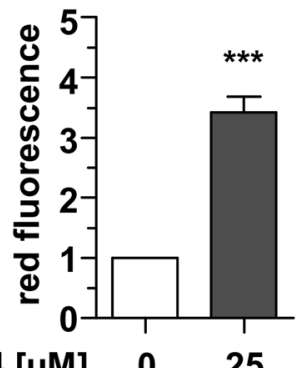

TH34 $[\mu \mathrm{M}] \quad 0 \quad 25$

To control for cytotoxic effects of TH34 on healthy cells, we treated proliferating non-malignant fibroblasts (VH7 cells) with this compound for $72 \mathrm{~h}$. In contrast to our findings in SK-N-BE(2)-C cells, TH34 exhibited very limited cytotoxic effects in fibroblasts (Fig. 2h). Taken together, these results indicate that cell death resulting from simultaneous
HDAC6, 8 and 10 inhibition is mainly a caspase-dependent programmed type of cell death, such as apoptosis.

To further compare the response of neuroblastoma cell lines to TH34 treatment, we investigated colony formation, cell viability, viable cell count and cellular metabolic activity in five neuroblastoma cell lines after treatment with 
४Fig. 1 TH34 inhibits HDACs 6, 8 and 10. a TH34 molecular structure. b Docking pose of TH34 (middle, cyan color) at HDAC8. c NanoBRET analysis of HDAC2/6/8/10 interaction with TH34 in HeLa cells. The number of biological replicates is $n=3$ for HDAC6 and HDAC 10 and $n=2$ for HDAC 2 and HDAC 8 and the number of technical replicates is $n=3$ for every independent run. Graph represents mean amounts of acceptor-occupied NanoLuc-HDAC2/6/8/10 relative to the total amount of NanoLuc-HDAC2/6/8/10 (\% fractional occupancy, $y$-axis) versus logarithmic drug concentration ( $x$-axis). Western Blot analysis of SMC3 (d), tubulin (e) and histone 3 acetylation (f) in SK-N-BE(2)-C cells after $6 \mathrm{~h}$ of treatment with TH34 $(25 \mu \mathrm{M})$ or solvent. g Flow-cytometric quantification of acridine orange-positive acidic vesicular organelles in SK-N-BE(2)-C neuroblastoma cells after $24 \mathrm{~h}$ of treatment. Bar graphs represent mean values of at least three independent experiments performed in triplicates and statistical analysis was performed using unpaired, two-tailed $t$ test $(* * * p<0.001 ; * * 0.001 \leq p<0.01 ; * 0.01 \leq p<0.05$, ns not significant). Error bars represent SD

increasing doses of TH34 (Fig. 3). These results indicate nuances in the responsiveness of neuroblastoma cell lines to HDAC6/8/10 inhibition. $M Y C N$-amplified cell lines (BE(2)-C, IMR-32, Kelly) tend to appear more sensitive to TH34 treatment than MYCN single-copy cell lines (SK-NAS and SH-SY5Y). In addition, the TP53 wildtype cell line IMR-32 was highly responsive in terms of cell death. Thus, although neuroblastoma cells are more sensitive to TH34 than cell lines of other tumor entities, even neuroblastoma cells show diverse responses, possibly related to different MYCN expression levels (amplification versus single copy).

\section{TH34 induces differentiation and cell cycle arrest in neuroblastoma cells}

As neuroblastoma arises from immature neuroblasts, differentiation induction is a pivotal part of current therapeutic regimens. HDAC8 has been identified to play a role in maintenance of an undifferentiated cellular phenotype (Rettig et al. 2015). We thus investigated whether TH34 treatment would enhance expression of neuronal differentiation markers. After $72 \mathrm{~h}$ of treatment with TH34, expression levels of the neurotrophic receptor tyrosine kinase 1 (NTRK1, Fig. 4a) significantly increased. In neuroblastoma, $N T R K 1$ expression is associated with benign clinical features (e.g., young age, favorable pathology and non-MYCN amplified genetic status), tumor cell differentiation and good outcome (Pajtler et al. 2014; Schramm et al. 2012). After 6 days of treatment with TH34, SK-N-BE(2)-C neuroblastoma cells markedly altered their morphology, characterized by formation of neurite-like structures (Fig. 4b). Under TH34 treatment, the neurites not only significantly increased in number (Fig. 4c) but also in length (Fig. 4d). Further underlining the differentiating effect of HDAC6/8/10 inhibition, SK-N-BE(2)-C cells treated with TH34 showed strongly positive neurofilament M (NEFM) staining (Fig. 4e). Low-micromolar doses of TH34 enhanced ATRA-induced morphological features of differentiation in a similar manner as we had previously described with the selective HDAC8 inhibitor PCI-34051 (Rettig et al. 2015) (Supplementary Fig. 3a). This drug combination also synergistically reduced neuroblastoma colony growth ( $\mathrm{CI}<0.1$ for $10 \mu \mathrm{M}$ of each) at concentrations of ATRA that can be maintained in human plasma (Adamson 1996) (Supplementary Fig. 3b-d).

To further characterize the effects mediated by TH34, we examined the expression of the cell cycle inhibitor CDKNIA (p21 $\left.{ }^{\mathrm{WAF} 1 / \mathrm{CIP} 1}\right)$. In response to cellular stress conditions, CDKN1A expression is induced through p53-dependent and -independent pathways (El-Deiry et al. 1993; Gartel and Tyner 1999, reviewed by; Jung et al. 2010). We found dosedependent upregulation of CDKNIA in both TP53-mutated (SK-N-BE(2)-C, Fig. 4f) and TP53-wild type neuroblastoma cells (IMR-32, Fig. 4g) after $72 \mathrm{~h}$ of TH34 treatment. Among living SK-N-BE(2)-C cells, we observed a marked shift from G0/G1 phase to S/G2/M phase after $72 \mathrm{~h}$ of TH34 treatment (Fig. 4h).

The protein SMC3 is a specific substrate for HDAC8 (Deardorff et al. 2012) and, together with structural maintenance of chromosomes 1A (SMC1), RAD21 and stromal antigen 1/2 (STAG1/2), SMC3 constitutes the cohesin complex, which forms a ring-like structure interconnecting sister chromatids during mitosis (Uhlmann 2016). SMC3 undergoes a cycle of deacetylation and acetylation, which is essential for cohesin functions (Beckouet et al. 2010). Although the impact of SMC3 hyperacetylation on mitosis and cell cycle progression remains to be fully elucidated, recent studies suggest that hyperacetylation inhibits sister chromatid release at anaphase (Beckouet et al. 2016; Gligoris et al. 2014). Since TH34 treatment induces hyperacetylation of SMC3 in high-grade neuroblastoma cells by blocking HDAC8 (Fig. 1d), we investigated if nuclear morphology and abundance of intact and aberrant mitotic figures changed under TH34 treatment. Indeed, 4',6-diamidino-2-phenylindole (DAPI) staining revealed a significantly higher number of mitotic cells after treatment with HDAC inhibitor TH34 (Fig. 4e, i). Moreover, TH34-treated cells much more frequently displayed increased nuclear size and mitoses with aberrant features such as multipolar or asymmetric spindles than control cells (Fig. 4e, j and Supplementary Fig. 4). Taken together, our results indicate that concomitant inhibition of HDACs 6, 8 and 10 induces signs of neuron-like differentiation, cell cycle arrest and mitotic aberrations in neuroblastoma cells.

\section{TH34 induces DNA damage in high-grade neuroblastoma cells}

Induction of DNA damage and inhibition of cellular DNA repair bear the potential to take advantage of malignant cells' dysfunctional DNA damage response mechanisms and thus 


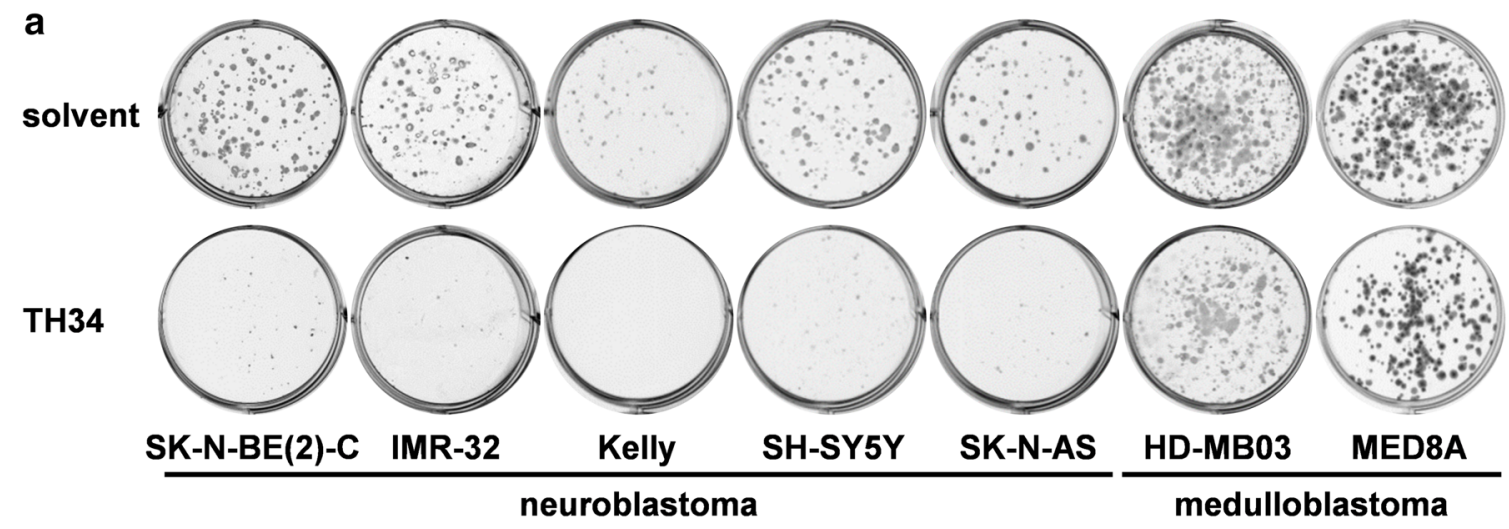

b
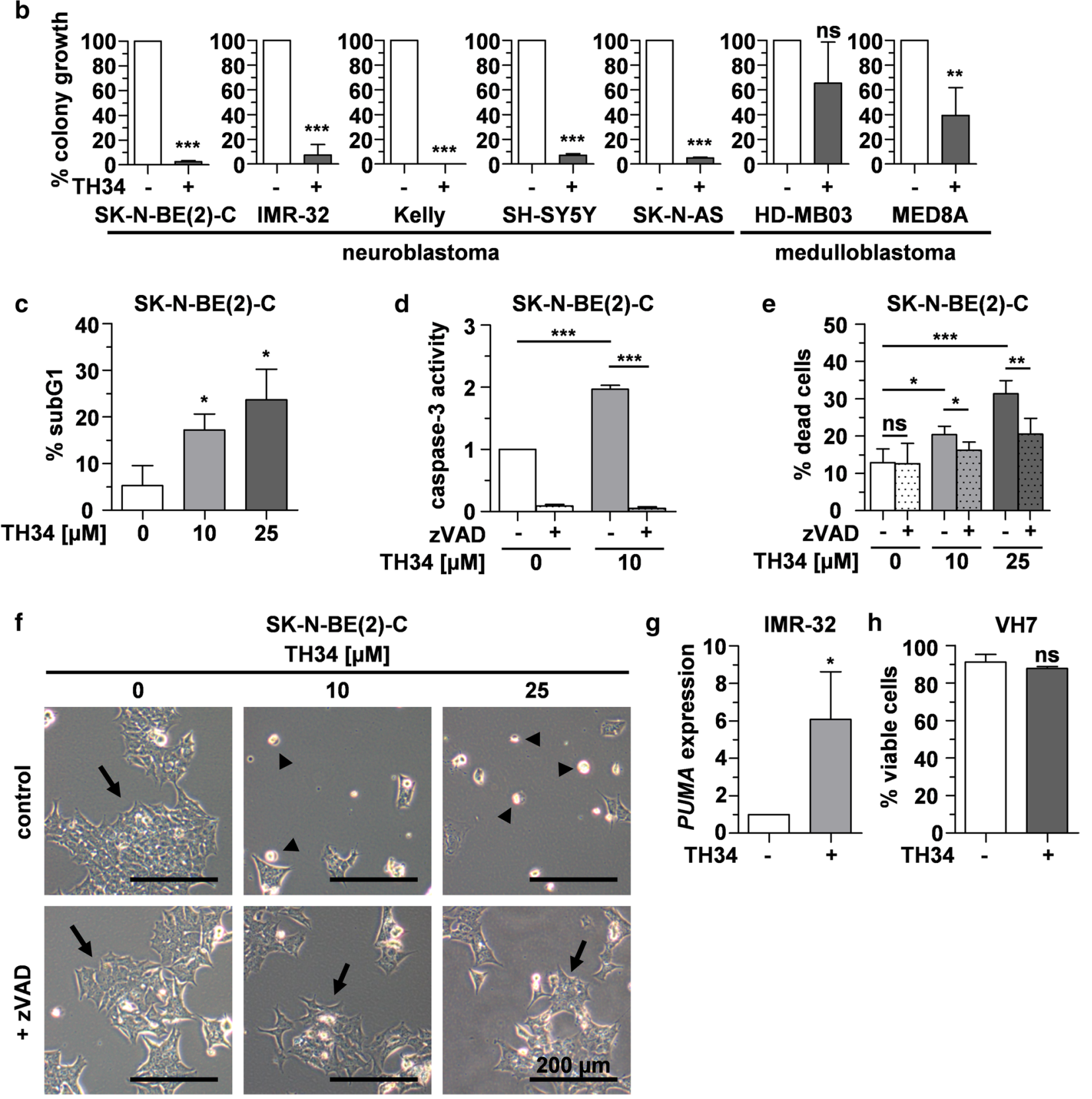
4Fig. 2 TH34 induces caspase-dependent programmed cell death in neuroblastoma cells. a, b Colony growth after treatment with TH34 $(25 \mu \mathrm{M})$ or solvent. Representative images and quantification of colony growth in at least three independent experiments performed in triplicates are shown for each cell line. $\mathbf{c}$ Fraction of cells in subG1 cell cycle phase after treatment with indicated concentrations of TH34 for $72 \mathrm{~h}$, identified via flow-cytometric quantification of DNA content using propidium iodide. $\mathbf{d}$ Caspase- 3 activity after treatment of SK-N-BE(2)-C cells with indicated concentrations of TH34 for $48 \mathrm{~h}$ with or without Z-VAD-FMK $(20 \mu \mathrm{M})$. e Proportion of dead SK-N-BE(2)-C cells after treatment with different concentrations of TH34 for $72 \mathrm{~h}$ with or without Z-VAD-FMK $(20 \mu \mathrm{M})$, determined via automated trypan blue staining. $\mathbf{f}$ Representative images of SK-N$\mathrm{BE}(2)-\mathrm{C}$ neuroblastoma cells treated with solvent or TH34 $(25 \mu \mathrm{M})$ with or without Z-VAD-FMK $(20 \mu \mathrm{M})$ for $72 \mathrm{~h}$. g Relative expression (determined using the $2^{-\Delta \Delta \mathrm{Ct}}$ method and normalized to solvent control) of PUMA in IMR-32 cells after $24 \mathrm{~h}$ of treatment with TH34 $(10 \mu \mathrm{M})$. (h) VH7 non-malignant fibroblast viability after treatment with solvent or TH34 $(25 \mu \mathrm{M})$ for $72 \mathrm{~h}$. Bar graphs represent mean values of at least three independent experiments performed in triplicates and statistical analysis was performed using unpaired, twotailed $t$ test $(* * * p<0.001 ; * * 0.001 \leq p<0.01 ; * 0.01 \leq p<0.05, n s$ not significant). Error bars represent SD

drive them into cell death while sparing non-malignant cells (Hosoya and Miyagawa 2014; Lord and Ashworth 2012). Treatment of cancer cells with broad-spectrum HDAC inhibitors such as vorinostat (suberoylanilide hydroxamic acid, SAHA) and trichostatin A (TSA) enhance DNA damage and impair non-homologous end joining (NHEJ) of DNA double-strand breaks (DSBs) (Lee et al. 2010; Pang et al. 2016; Robert et al. 2016; Vashishta and Hetman 2014). The exact role of single HDAC subtypes including HDAC8 and HDAC10 in DNA damage repair, however, is not yet fully understood.

Thus, we investigated whether mutual inhibition of HDACs 6, 8 and 10 affected DNA integrity. Flow-cytometric analysis of H2AX phospho-S134 $(\gamma \mathrm{H} 2 \mathrm{AX})$ in viable SK-N$\mathrm{BE}(2)-\mathrm{C}$ cells revealed a dose-dependent significant increase in $\gamma \mathrm{H} 2 \mathrm{AX}$-positive cells after treatment with TH34 for $24 \mathrm{~h}$ (Fig. 5a-c). Immunofluorescence staining of $\gamma \mathrm{H} 2 \mathrm{AX}$ indicated nuclear foci in TH34-, but not solvent-treated highgrade neuroblastoma cells, confirming dose-dependent occurrence of DSBs under HDAC6/8/10 inhibition (Fig. 5d). Of note, we did not observe relevantly decreased cell viability nor aberrant mitotic figures in SK-N-BE(2)-C cells after $24 \mathrm{~h}$ of treatment with TH34, meaning that DNA damage occurred prior to cell death of neuroblastoma cells (Fig. 5e).

As DNA double-strand breaks can result from caspase activation (Rogakou et al. 2000), we aimed to rule out unspecific $\gamma \mathrm{H} 2 \mathrm{AX}$ positivity due to caspase activation. Thus, we analyzed whether $1 \mathrm{~h}$ of Z-VAD-FMK pre-treatment of SK-N-BE(2)-C cells and additional treatment with different concentrations of TH34 for $24 \mathrm{~h}$ affects TH34induced $\gamma \mathrm{H} 2 \mathrm{AX}$ positivity in SK-N-BE(2)-C cells. Again, treatment of cells with TH34 dose-dependently increased $\gamma \mathrm{H} 2 \mathrm{AX}$-positivity, which was unaffected by Z-VAD-FMK co-treatment (Fig. 5f-i). Finally, we investigated the effect of a combined inhibition of HDAC6, 8 and 10 in shortterm cultures of primary neuroblastoma cells isolated from a $M Y C N$-amplified INSS stage 4 tumor of a 1-month-old patient (NB8). Here, TH34 treatment also dose-dependently increased $\gamma \mathrm{H} 2 \mathrm{AX}$-positive cells after $24 \mathrm{~h}$, albeit with a relatively small effect size (Fig. 5j-1). Treatment of NB8 cells with increasing doses of TH34 revealed a reduction of cellular metabolic activity at micromolar doses, with an IC50 of $47.3 \mu \mathrm{M}$ (Fig. $5 \mathrm{~m}$ ), which is slightly higher than that of Kelly cells (39.1 $\mu$ M, Fig. 3). In summary, TH34 induces DNA damage independent of caspase activation prior to triggering caspase-dependent programmed cell death in highgrade- and primary neuroblastoma cells.

\section{Discussion}

As a consequence of the pivotal roles of HDACs in various diseases including cancer, disruption of their activity with broad-spectrum or subtype-specific inhibitors has garnered strong interest in preclinical research and drug discovery (Witt et al. 2009a). With the development of techniques such as X-ray-based crystal structure analysis and computational approaches, a variety of novel selective HDAC inhibitors have emerged for laboratory and clinical application. We have previously identified high HDAC 8 and HDAC10 expression to correlate with poor outcomes in neuroblastoma and high-grade neuroblastoma, respectively. In line with this, treatment of high-grade neuroblastoma cells with the selective HDAC8 inhibitor PCI-34051 induces cellular differentiation (Rettig et al. 2015) and the class IIb HDAC inhibitor tubastatin A interferes with lysosomal trafficking and cellular stress-response mechanisms such as autophagy, rendering tumor cells more susceptible to cytotoxic treatment (Oehme et al. 2013). We thus aimed to develop an HDAC inhibitor with a target spectrum covering HDACs 8 and 10 and sparing HDACs 1, 2 and 3, as dose-limiting side effects of clinically used HDAC inhibitors are attributed to the inhibition of these HDAC subtypes (Witt et al. 2009b).

Here, we describe the newly developed HDAC6/8/10 inhibitor TH34, identified in a screen, in which novel HDAC inhibitory compounds were evaluated for their on- and off-target activities via phenotypical assays and analysis of protein acetylation patterns. TH34 treatment induced hyperacetylation of tubulin and SMC3, established bona fide substrates of HDAC6 and 8, respectively, indicating inhibition of these HDAC subtypes (Deardorff et al. 2012; Decroos et al. 2015). Although even more candidate HDAC8 substrates were recently identified via genetically encoded active site photo-crosslinking (Lopez et al. 2017), the identification of HDAC10-specific substrates remains difficult. To date, no antibody 

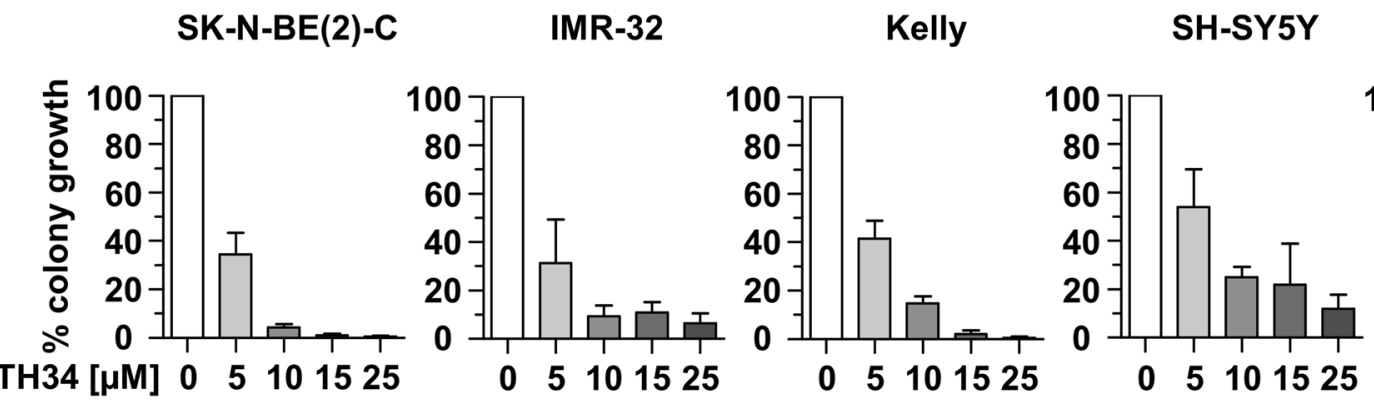

SK-N-AS
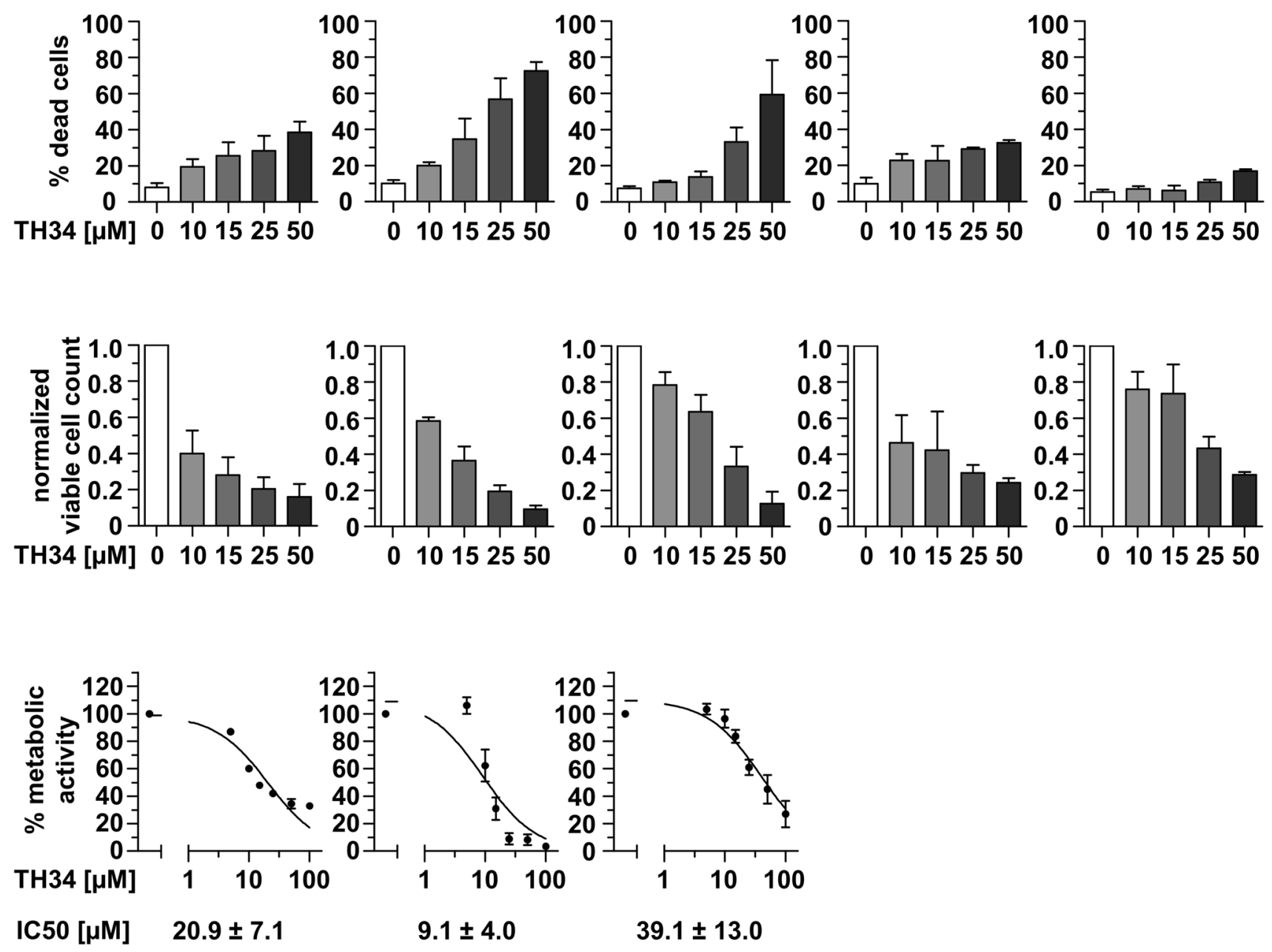

Fig. 3 TH34 differentially impairs colony formation and cell survival in neuroblastoma cell lines with distinct molecular features. Relative colony formation, proportion of dead cells and viable cell count (both determined via trypan blue exclusion assay) as well as metabolic activity (CellTiter-Glo) in five different neuroblastoma cell lines (SK-

N-BE(2)-C, IMR-32, Kelly, SH-SY5Y and SK-N-AS) after treatment with indicated concentrations of TH34. Bar graphs represent mean values of at least two independent experiments performed in triplicates each and error bars represent SD

against a bona fide-acetylated HDAC10 substrate has been described. Accumulation of acidic vesicular organelles has been shown to be directly linked to HDAC10 inhibition and quantification of this phenotype can be used to measure cellular HDAC10 activity. As such, TH34 treatment induced strong accumulation of acidic vesicular organelles. 

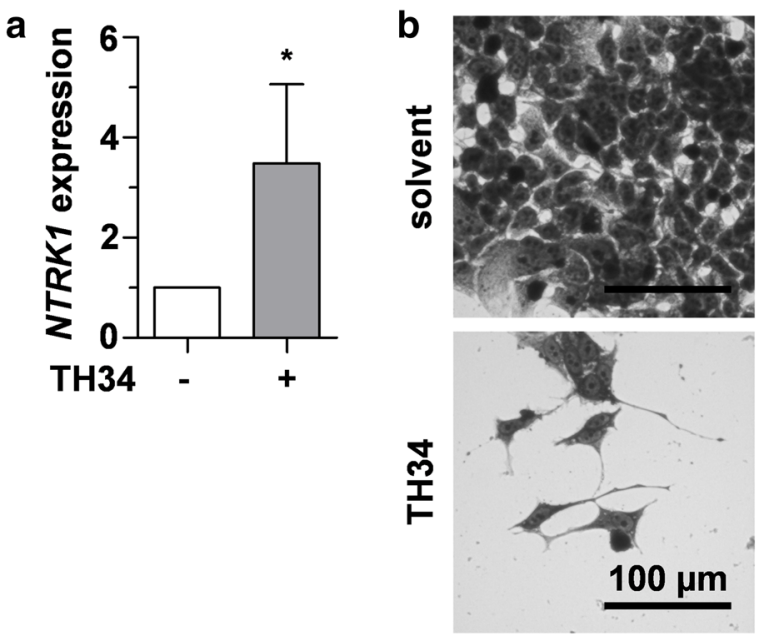

C

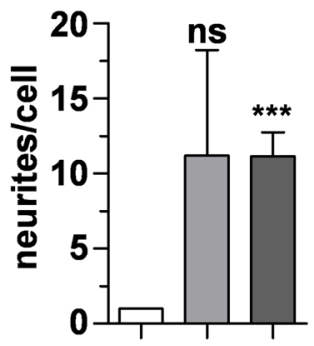

TH34 [ $\mu \mathrm{M}] \quad 0 \quad 1025$ d

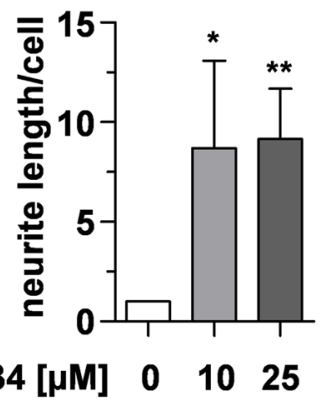

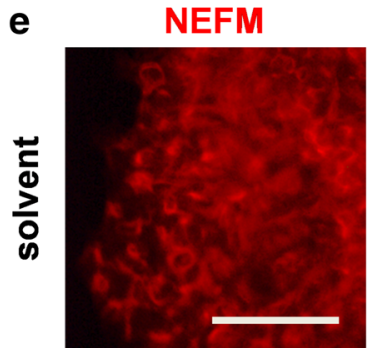
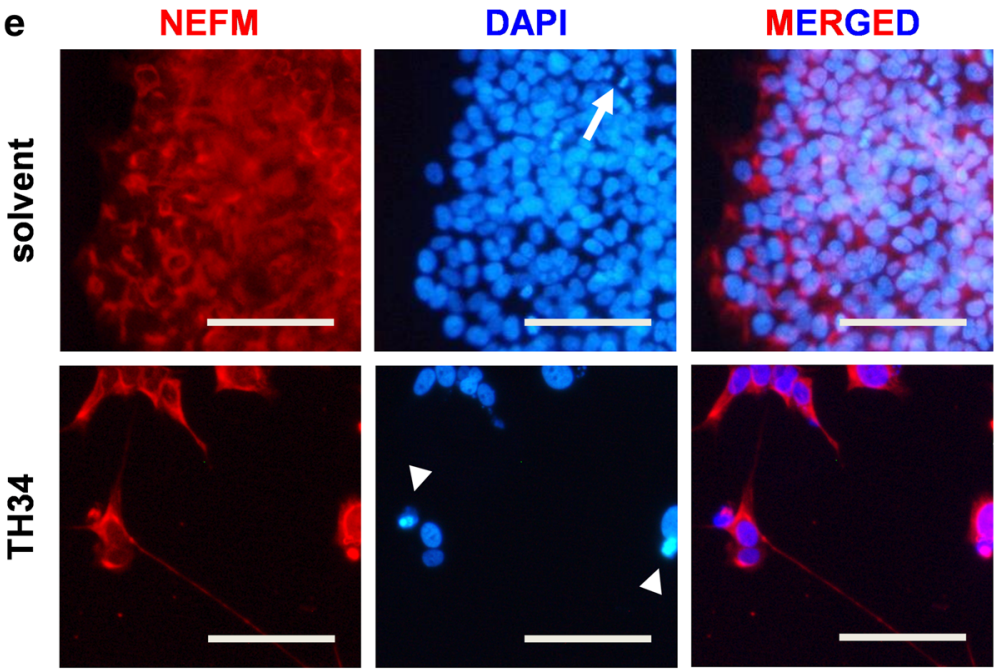

f

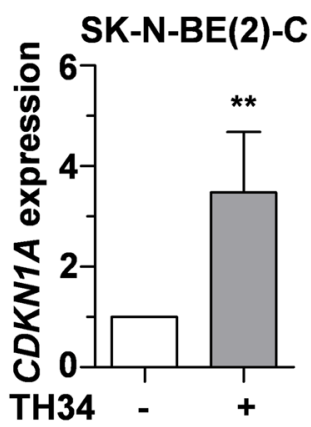

g

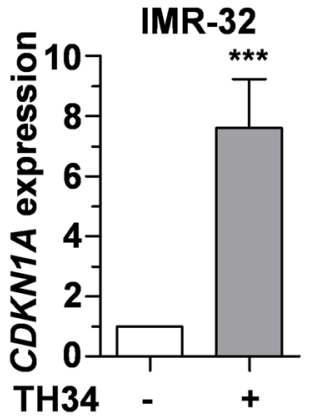

h

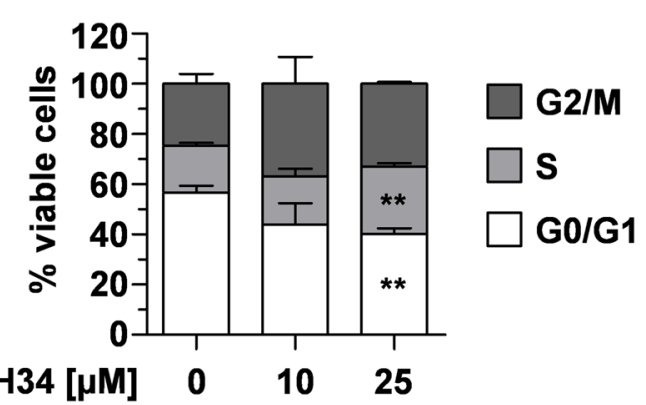

Fig. 4 TH34 induces differentiation and cell cycle arrest in neuroblastoma cells. a Relative expression (determined using the $2^{-\Delta \Delta \mathrm{Ct}}$ method and normalized to solvent control) of NTRK1 in SK-N-BE(2)-C neuroblastoma cells after $72 \mathrm{~h}$ of treatment with TH34 $(10 \mu \mathrm{M})$. b Representative microscopic images of crystal violet-stained SK-N-BE(2)-C cells treated with TH34 $(10 \mu \mathrm{M})$ for 6 days. c-d Relative number and length of neurites in SK-N-BE(2)-C cells after 6 days of treatment with indicated concentrations of TH34, quantified using a semi-automated macro determining surface of cell bodies as well as number and length of neurites in ten fields of vision in ImageJ version $1.49 \mathrm{v}$ and normalized to solvent control. e Fluorescence microscopic analysis of neurofilament $\mathrm{M}$ expression in SK-N-BE(2)-C cells treated with $\mathrm{TH} 34(10 \mu \mathrm{M})$ for 6 days. Nuclei were counterstained with DAPI, arrows and arrowheads indicate normal mitotic and aberrant mitotic nuclei, respectively. Relative expres-
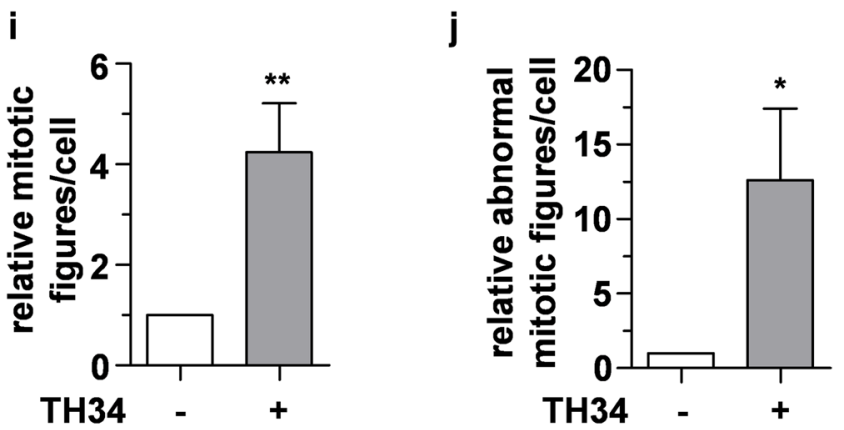

sion (determined using the $2^{-\Delta \Delta \mathrm{Ct}}$ method and normalized to solvent control) of CDKN1A in SK-N-BE(2)-C (f) and IMR-32 (g) neuroblastoma cells after $72 \mathrm{~h}$ of treatment with TH34 $(10 \mu \mathrm{M})$. h Cell cycle distribution of viable SK$\mathrm{N}-\mathrm{BE}(2)-\mathrm{C}$ cells in G0/G1 (white), S (light gray) and G2/M (dark gray) phase after $72 \mathrm{~h}$ of treatment with indicated concentrations of TH34. i, j Total and aberrant mitotic nuclei in SK-N-BE(2)-C neuroblastoma cells after 6 days of treatment with TH34 $(10 \mu \mathrm{M})$. In ten fields of vision, all DAPI-stained nuclei and mitotic figures were counted using the Cell Counter Plugin for ImageJ version $1.49 \mathrm{v}$ and numbers obtained in treated samples were set in relation to solvent control. Bar graphs represent mean values of at least three independent experiments and statistical analysis was performed using unpaired, two-tailed $t$ test $(* * * p<0.001 ; * * 0.001 \leq p<0.01 ; * 0.01 \leq p<0.05$, ns not significant). Error bars represent SD 


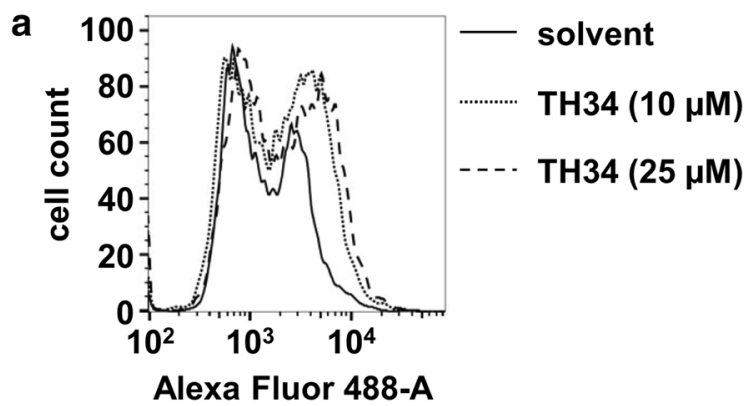

b

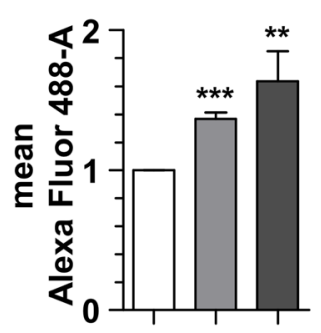

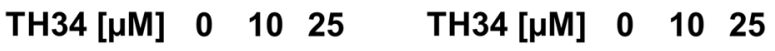

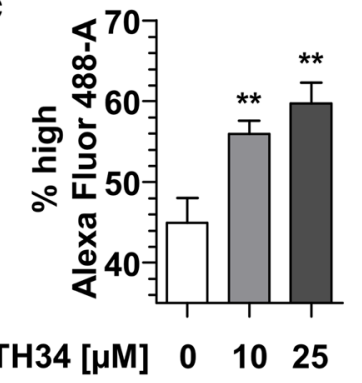

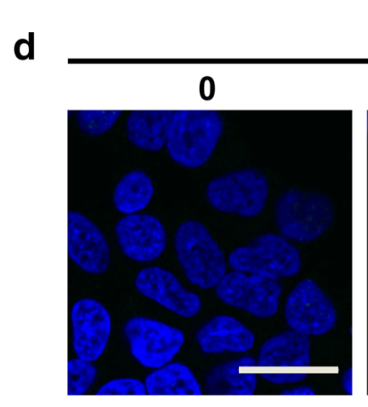

TH34 [ $\mu \mathrm{M}]$

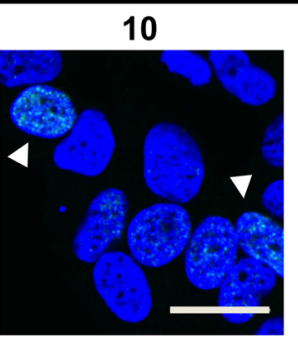

f

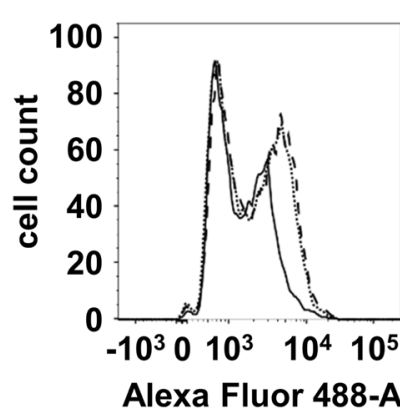

h

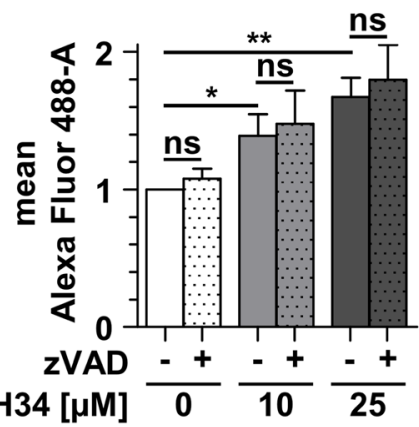

solvent

TH34 $(10 \mu \mathrm{M})$

TH34 $(10 \mu \mathrm{M})+$ zVAD $(40 \mu \mathrm{M})$

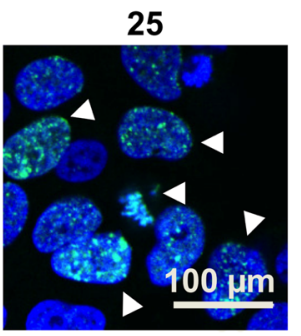

YH2A.X DAPI

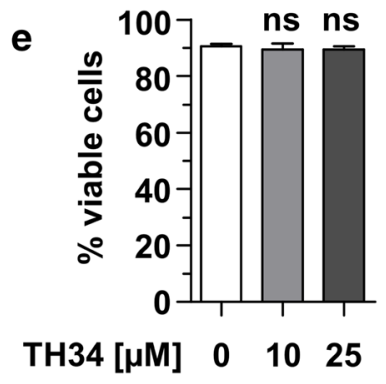


4Fig. 5 TH34 induces DNA damage in high-grade neuroblastoma cells. a Flow cytometric analysis of H2AX S134 phosphorylation $(\gamma \mathrm{H} 2 \mathrm{AX})$ in fixed, viable SK-N-BE(2)-C cells after $24 \mathrm{~h}$ of treatment with indicated concentrations of TH34. Figure shows histogram of logarithmic fluorescence ( $x$-axis) versus event number ( $y$-axis) and gate represents $\gamma \mathrm{H} 2 \mathrm{AX}$-positive cells. Mean Alexa Fluor 488 fluorescence (b) and proportion of $\gamma \mathrm{H} 2 \mathrm{AX}$-positive cells (c) after treatment of SK-N-BE(2)-C cells with different concentrations of TH34 for $24 \mathrm{~h}$. d Immunofluorescence analysis of $\gamma \mathrm{H} 2 \mathrm{AX}$ staining on fixed SK-N-BE(2)-C cells after $24 \mathrm{~h}$ of treatment with indicated concentrations of TH34. Nuclei were counterstained with DAPI, and arrowheads indicate nuclei with high number of DNA double-strand breaks. e Proportion of dead SK-N-BE(2)-C cells after treatment with different concentrations of TH34 for $24 \mathrm{~h}$, determined via automated trypan blue staining. f, g Flow cytometric analysis of H2AX S134 phosphorylation $(\gamma \mathrm{H} 2 \mathrm{AX})$ in fixed viable SK-N-BE(2)-C cells after $1 \mathrm{~h}$ of pre-treatment with Z-VAD-FMK $(40 \mu \mathrm{M})$ alone and $24 \mathrm{~h}$ of additional treatment with TH34 at a concentration of $10 \mu \mathrm{M}$ (f) or $25 \mu \mathrm{M}(\mathrm{g})$. Figure shows histogram of logarithmic fluorescence ( $x$-axis) versus event number ( $y$-axis) and gate represents $\gamma \mathrm{H} 2 \mathrm{AX}$ -positive cells. Mean Alexa Fluor 488 fluorescence (h) and proportion of $\gamma \mathrm{H} 2 \mathrm{AX}$-positive cells (i) after $1 \mathrm{~h}$ of Z-VAD-FMK $(40 \mu \mathrm{M})$ pre-treatment of SK-N-BE(2)-C cells and additional treatment with different concentrations of TH34 for $24 \mathrm{~h}$. j Flow cytometric analysis of H2AX S134 phosphorylation $(\gamma \mathrm{H} 2 \mathrm{AX})$ in fixed viable NB8 primary neuroblastoma cells after $24 \mathrm{~h}$ of treatment with indicated concentrations of TH34. Figure shows histogram of logarithmic fluorescence ( $x$-axis) versus event number ( $y$-axis) and gate represents $\gamma \mathrm{H} 2 \mathrm{AX}$-positive cells. Mean Alexa Fluor 488 fluorescence $(\mathbf{k})$ and proportion of $\gamma \mathrm{H} 2 \mathrm{AX}$ highly positive cells (l) after treatment of NB8 primary neuroblastoma cells with different concentrations of TH34 for $24 \mathrm{~h}$. (m) Cellular metabolic activity (CellTiter-Glo) of NB8 primary neuroblastoma cells after treatment with indicated concentrations of TH34 for $72 \mathrm{~h}$. Bar graphs represent mean values of at least three independent experiments and statistical analysis was performed using unpaired, two-tailed $t$ test $(* * * p<0.001 ; * * 0.001 \leq p<0.01$; $* 0.01 \leq p<0.05, n s$ not significant). Error bars represent SD

Throughout the cell cycle, SMC3 undergoes a cycle of acetylation and deacetylation, which is essential for the functions of the cohesin complex consisting of SMC1, RAD21, STAG1/2 and SMC3. This complex mediates sister chromatid cohesion during mitosis by forming a connecting ring in $\mathrm{S}$ phase, which disintegrates during mitotic anaphase, guaranteeing equal distribution of chromatids (Beckouet et al. 2010). As recent studies suggest that SMC3 hyperacetylation inhibits sister chromatid release at anaphase (Beckouet et al. 2016; Gligoris et al. 2014), it is conceivable that the HDAC8 inhibitory function of TH34 is responsible for the increase of mitotic aberrations and G2/M cell cycle arrest in neuroblastoma cells after treatment with the novel HDAC6/8/10 inhibitor.

Recent advances in HDAC10 research include the identification of its crystal structure, which provided evidence that HDAC10 might be a polyamine rather than a lysine deacetylase (Hai et al. 2017). In neuroblastoma, the polyamine regulating $O D C l$ was found co-upregulated with $M Y C N$ and correlates with poor outcome in neuroblastoma, suggesting a detrimental role in neuroblastoma biology (Gamble et al. 2012; Hogarty et al. 2008; Lastowska et al. 2007).
Moreover, polyamines are known to modulate DNA conformation by strongly binding to the DNA helix (Feuerstein et al. 1990; Matthews 1993), and recently identified roles of HDAC10 include regulation of DNA mismatch and DSB repair in various cancer types such as ovarian carcinoma (Islam et al. 2017; Radhakrishnan et al. 2015). DNA damage has also been described as a result of HDAC6 depletion and inhibition (Namdar et al. 2010; Wang et al. 2012), and the above-mentioned HDAC8-dependent cohesin complex is well known to accumulate at DNA break sites to mediate DNA repair and recruit cell cycle checkpoint-activating proteins (Caron et al. 2012; Watrin and Peters 2009). We thus hypothesized that combined HDAC6/8/10 inhibition affects DNA damage repair mechanisms. During the first $24 \mathrm{~h}$ of treatment with the HDAC6/8/10 inhibitor TH34, we detected a marked increase in $\gamma \mathrm{H} 2 \mathrm{AX}$ foci, providing strong evidence of the involvement of HDACs 6, 8 and 10 in DNA damage repair mechanisms in neuroblastoma. Importantly, this effect could not be reverted by co-treatment with the caspase inhibitor Z-VAD-FMK, indicating that DSB accumulation under TH34 treatment is a process independent of caspase activation.

Overall, these results qualify TH34 as a promising targeted agent for further development as a neuroblastoma therapeutic, including in vivo toxicity and efficacy testing. However, physiologically relevant aspects, not covered by our study, such as metabolic half life and immunosuppression by HDAC inhibitors, especially class IIb HDAC inhibitors (Kalin et al. 2012), which might limit applicability and anti-tumoral efficacy of TH34 in immunocompetent organisms, are mandatory to be evaluated in future studies. In conclusion, the selective HDAC6/8/10 inhibitor TH34 effectively and selectively eliminates highgrade neuroblastoma cells while sparing non-transformed human cells. In neuroblastoma cell lines as well as primary neuroblastoma cells, it markedly induces DNA damage, followed by differentiation and G2/M phase cell cycle arrest at later timepoints, eventually leading to cell death. Besides its potential as a targeted therapeutic in high-grade neuroblastoma, TH34 also serves as a valuable tool compound in laboratory research for investigating the roles of histone deacetylases in health and disease.

Acknowledgements The authors thank Ramona Straub, Annika Bittmann, Aileen Mangang and Paula Eiben for excellent technical assistance. Anti-acetylated SMC3 antibody was generously provided by Katsuhiko Shirahige (Institute for Molecular and Cellular Biosciences, University of Tokyo, Japan). We would like to acknowledge Dr. Damir Krunic from the light microscopy core facility at the DKFZ who gave important input on analysis of cellular images using macros in ImageJ version 1.49v. We thank Prof. Dr. Oliver H. Krämer, Department of Toxicology, University Medical Center Mainz for important scientific input. This work was supported by funding from the German Research Foundation (DFG) to WS (Si868/13-1), MJ (Ju295/13-1), OW (W1461/4-1) and IO (Oe542/2-1) and from the H.W.\&J. Hector 
foundation to IO (Grant reference number: M71). FRK and MM were supported by the German Cancer Aid with Mildred Scheel doctoral scholarships (numbers 112065 and 70113124).

Author contributions FRK designed and conducted experiments, analyzed data and wrote the paper. EK and JR helped with data acquisition and analysis and gave important scientific input. MM conducted and analyzed CellTiter-Glo experiments. TH, TB, WS and MJ provided candidate inhibitors including TH34. NG and AKM provided NanoBRET data. FW isolated and established NB8 primary neuroblastoma cells. OW and IO supervised the project and provided funding, and IO further conceptualized experiments, analyzed data and wrote the paper. All authors read and approved the manuscript.

\section{Compliance with ethical standards}

Conflict of interest The authors declare no conflicts of interest.

Open Access This article is distributed under the terms of the Creative Commons Attribution 4.0 International License (http://creativeco mmons.org/licenses/by/4.0/), which permits unrestricted use, distribution, and reproduction in any medium, provided you give appropriate credit to the original author(s) and the source, provide a link to the Creative Commons license, and indicate if changes were made.

\section{References}

Adamson PC (1996) All-trans-retinoic acid pharmacology and its impact on the treatment of acute promyelocytic leukemia. Oncologist 1(5):305-314

Balasubramanian S, Verner E, Buggy JJ (2009) Isoform-specific histone deacetylase inhibitors: the next step? Cancer Lett 280(2):211-221. https://doi.org/10.1016/j.canlet.2009.02.013

Bates SE, Eisch R, Ling A et al (2015) Romidepsin in peripheral and cutaneous T-cell lymphoma: mechanistic implications from clinical and correlative data. Br J Haematol 170(1):96-109. https://doi.org/10.1111/bjh.13400

Beckouet F, Hu B, Roig MB et al (2010) An Smc3 acetylation cycle is essential for establishment of sister chromatid cohesion. Mol Cell 39(5):689-699. https://doi.org/10.1016/j.molce 1.2010.08.008

Beckouet F, Srinivasan M, Roig MB et al (2016) Releasing activity disengages cohesin's Smc3/Scc1 interface in a process blocked by acetylation. Mol Cell 61(4):563-574. https://doi.org/10.1016/j. molcel.2016.01.026

Bradner JE, West N, Grachan ML et al (2010) Chemical phylogenetics of histone deacetylases. Nat Chem Biol 6(3):238-243. https://doi. org/10.1038/nchembio. 313

Brodeur GM (2003) Neuroblastoma: biological insights into a clinical enigma. Nat Rev Cancer 3(3):203-216. https://doi.org/10.1038/ $\operatorname{nrc} 1014$

Caron P, Aymard F, Iacovoni JS et al (2012) Cohesin protects genes against gamma $\mathrm{H} 2 \mathrm{AX}$ induced by DNA double-strand breaks. PLoS Genet 8(1):e1002460. https://doi.org/10.1371/journ al.pgen. 1002460

Cheng T, Grasse L, Shah J, Chandra J (2015) Panobinostat, a panhistone deacetylase inhibitor: rationale for and application to treatment of multiple myeloma. Drugs Today (Barc) 51(8):491-504. https://doi.org/10.1358/dot.2015.51.8.2362311

Cheung NK, Dyer MA (2013) Neuroblastoma: developmental biology, cancer genomics and immunotherapy. Nat Rev Cancer 13(6):397411. https://doi.org/10.1038/nrc3526
Chou TC (2010) Drug combination studies and their synergy quantification using the Chou-Talalay method. Cancer Res 70(2):440446. https://doi.org/10.1158/0008-5472.CAN-09-1947

de Ruijter AJ, van Gennip AH, Caron HN, Kemp S, van Kuilenburg AB (2003) Histone deacetylases (HDACs): characterization of the classical HDAC family. Biochem J 370(Pt 3):737-749. https://doi. org/10.1042/BJ20021321

Deardorff MA, Bando M, Nakato R et al (2012) HDAC8 mutations in Cornelia de Lange syndrome affect the cohesin acetylation cycle. Nature 489(7415):313-317. https://doi.org/10.1038/nature11316

Decroos C, Christianson NH, Gullett LE et al (2015) Biochemical and structural characterization of HDAC8 mutants associated with Cornelia de Lange syndrome spectrum disorders. Biochemistry 54(42):6501-6513. https://doi.org/10.1021/acs.biochem.5b00881

Ecker J, Oehme I, Mazitschek R et al (2015) Targeting class I histone deacetylase 2 in MYC amplified group 3 medulloblastoma. Acta Neuropathol Commun 3:22. https://doi.org/10.1186/s4047 8-015-0201-7

El-Deiry WS, Tokino T, Velculescu VE et al (1993) WAF1, a potential mediator of p53 tumor suppression. Cell 75(4):817-825

Feuerstein BG, Pattabiraman N, Marton LJ (1990) Molecular mechanics of the interactions of spermine with DNA: DNA bending as a result of ligand binding. Nucleic Acids Res 18(5):1271-1282

Fischer DD, Cai R, Bhatia U et al (2002) Isolation and characterization of a novel class II histone deacetylase, HDAC10. J Biol Chem 277(8):6656-6666. https://doi.org/10.1074/jbc.M108055200

Fischer M, Skowron M, Berthold F (2005) Reliable transcript quantification by real-time reverse transcriptase-polymerase chain reaction in primary neuroblastoma using normalization to averaged expression levels of the control genes HPRT1 and SDHA. J Mol Diagn 7(1):89-96

Gamble LD, Hogarty MD, Liu X et al (2012) Polyamine pathway inhibition as a novel therapeutic approach to treating neuroblastoma. Front Oncol 2:162. https://doi.org/10.3389/fonc.2012.00162

Gartel AL, Tyner AL (1999) Transcriptional regulation of the p21((WAF1/CIP1)) gene. Exp Cell Res 246(2):280-289. https:// doi.org/10.1006/excr.1998.4319

Gligoris TG, Scheinost JC, Burmann F et al (2014) Closing the cohesin ring: structure and function of its Smc3-kleisin interface. Science 346(6212):963-967. https://doi.org/10.1126/scien ce. 1256917

Hai Y, Shinsky SA, Porter NJ, Christianson DW (2017) Histone deacetylase 10 structure and molecular function as a polyamine deacetylase. Nat Commun 8:15368. https://doi.org/10.1038/ncomm s15368

Heimburg T, Chakrabarti A, Lancelot J et al (2016) Structure-based design and synthesis of novel inhibitors targeting HDAC8 from Schistosoma mansoni for the treatment of schistosomiasis. J Med Chem 59(6):2423-2435. https://doi.org/10.1021/acs.jmedc hem. $5 \mathrm{~b} 01478$

Heimburg T, Kolbinger FR, Zeyen P et al (2017) Structure-based design and biological characterization of selective histone deacetylase 8 (HDAC8) inhibitors with anti-neuroblastoma activity. J Med Chem. https://doi.org/10.1021/acs.jmedchem.7b01447

Hogarty MD, Norris MD, Davis K et al (2008) ODC1 is a critical determinant of MYCN oncogenesis and a therapeutic target in neuroblastoma. Cancer Res 68(23):9735-9745. https://doi. org/10.1158/0008-5472.CAN-07-6866

Hosoya N, Miyagawa K (2014) Targeting DNA damage response in cancer therapy. Cancer Sci 105(4):370-388. https://doi. org/10.1111/cas.12366

Islam MM, Banerjee T, Packard CZ et al (2017) HDAC10 as a potential therapeutic target in ovarian cancer. Gynecol Oncol 144(3):613620. https://doi.org/10.1016/j.ygyno.2017.01.009 
Jung YS, Qian Y, Chen X (2010) Examination of the expanding pathways for the regulation of $\mathrm{p} 21$ expression and activity. Cell Signal 22(7):1003-1012. https://doi.org/10.1016/j.cellsig.2010.01.013

Kalin JH, Butler KV, Akimova T, Hancock WW, Kozikowski AP (2012) Second-generation histone deacetylase 6 inhibitors enhance the immunosuppressive effects of Foxp3 + T-regulatory cells. J Med Chem 55(2):639-651. https://doi.org/10.1021/jm200 $773 \mathrm{~h}$

Kawaguchi Y, Kovacs JJ, McLaurin A, Vance JM, Ito A, Yao TP (2003) The deacetylase HDAC6 regulates aggresome formation and cell viability in response to misfolded protein stress. Cell 115(6):727-738

Kim MS, Kwon HJ, Lee YM et al (2001) Histone deacetylases induce angiogenesis by negative regulation of tumor suppressor genes. Nat Med 7(4):437-443. https://doi.org/10.1038/86507

Koeneke E, Witt O, Oehme I (2015) HDAC family members intertwined in the regulation of autophagy: a druggable vulnerability in aggressive tumor entities. Cells 4(2):135-168. https://doi. org/10.3390/cells4020135

Kramer OH, Mahboobi S, Sellmer A (2014) Drugging the HDAC6HSP90 interplay in malignant cells. Trends Pharmacol Sci 35(10):501-509. https://doi.org/10.1016/j.tips.2014.08.001

Lane AA, Chabner BA (2009) Histone deacetylase inhibitors in cancer therapy. J Clin Oncol 27(32):5459-5468. https://doi.org/10.1200/ JCO.2009.22.1291

Lastowska M, Viprey V, Santibanez-Koref M et al (2007) Identification of candidate genes involved in neuroblastoma progression by combining genomic and expression microarrays with survival data. Oncogene 26(53):7432-7444. https://doi.org/10.1038/ sj.onc. 1210552

Lee JH, Choy ML, Ngo L, Foster SS, Marks PA (2010) Histone deacetylase inhibitor induces DNA damage, which normal but not transformed cells can repair. Proc Natl Acad Sci USA 107(33):1463914644. https://doi.org/10.1073/pnas.1008522107

Li Z, Zhu WG (2014) Targeting histone deacetylases for cancer therapy: from molecular mechanisms to clinical implications. Int $\mathbf{J}$ Biol Sci 10(7):757-770. https://doi.org/10.7150/ijbs.9067

Livak KJ, Schmittgen TD (2001) Analysis of relative gene expression data using real-time quantitative PCR and the 2(-Delta Delta C(T)) method. Methods 25(4):402-408. https://doi.org/10.1006/ meth.2001.1262

Lopez JE, Haynes SE, Majmudar JD, Martin BR, Fierke CA (2017) HDAC8 substrates identified by genetically encoded active site photocrosslinking. J Am Chem Soc 139(45):16222-16227. https ://doi.org/10.1021/jacs.7b07603

Lord CJ, Ashworth A (2012) The DNA damage response and cancer therapy. Nature 481(7381):287-294. https://doi.org/10.1038/ nature 10760

Mann BS, Johnson JR, Cohen MH, Justice R, Pazdur R (2007) FDA approval summary: vorinostat for treatment of advanced primary cutaneous T-cell lymphoma. Oncologist 12(10):12471252. https://doi.org/10.1634/theoncologist.12-10-1247

Mariotti LG, Pirovano G, Savage KI et al (2013) Use of the gamma$\mathrm{H} 2 \mathrm{AX}$ assay to investigate DNA repair dynamics following multiple radiation exposures. PLoS One 8(11):e79541. https:// doi.org/10.1371/journal.pone.0079541

Matthews HR (1993) Polyamines, chromatin structure and transcription. Bioessays 15(8):561-566. https://doi.org/10.1002/ bies. 950150811

Miller KM, Tjeertes JV, Coates J et al (2010) Human HDAC1 and HDAC2 function in the DNA-damage response to promote DNA nonhomologous end-joining. Nat Struct Mol Biol 17(9):11441151. https://doi.org/10.1038/nsmb.1899

Muslimovic A, Ismail IH, Gao Y, Hammarsten O (2008) An optimized method for measurement of gamma-H2AX in blood mononuclear and cultured cells. Nat Protoc 3(7):1187-1193. https://doi.org/10.1038/nprot.2008.93

Namdar M, Perez G, Ngo L, Marks PA (2010) Selective inhibition of histone deacetylase 6 (HDAC6) induces DNA damage and sensitizes transformed cells to anticancer agents. Proc Natl Acad Sci USA 107(46):20003-20008. https://doi.org/10.1073/ pnas. 1013754107

Nikolova T, Kiweler N, Kramer OH (2017) Interstrand crosslink repair as a target for HDAC inhibition. Trends Pharmacol Sci 38(9):822-836. https://doi.org/10.1016/j.tips.2017.05.009

Nishiyama T, Ladurner R, Schmitz J et al (2010) Sororin mediates sister chromatid cohesion by antagonizing Wapl. Cell 143(5):737-749. https://doi.org/10.1016/j.cell.2010.10.031

O'Connor OA, Horwitz S, Masszi T et al (2015) Belinostat in patients with relapsed or refractory peripheral T-cell lymphoma: results of the pivotal phase II BELIEF (CLN-19) Study. J Clin Oncol 33(23):2492-2499. https://doi.org/10.1200/ JCO.2014.59.2782

Oehme I, Bosser S, Zornig M (2006) Agonists of an ecdysoneinducible mammalian expression system inhibit Fas Ligand- and TRAIL-induced apoptosis in the human colon carcinoma cell line RKO. Cell Death Differ 13(2):189-201. https://doi.org/10.1038/ sj.cdd. 4401730

Oehme I, Deubzer HE, Lodrini M, Milde T, Witt O (2009a) Targeting of HDAC8 and investigational inhibitors in neuroblastoma. Expert Opin Investig Drugs 18(11):1605-1617. https://doi. org/10.1517/14728220903241658

Oehme I, Deubzer HE, Wegener D et al (2009b) Histone deacetylase 8 in neuroblastoma tumorigenesis. Clin Cancer Res Off J Am Assoc Cancer Res 15(1):91-99. https://doi.org/10.1158/10780432.CCR-08-0684

Oehme I, Linke JP, Bock BC et al (2013) Histone deacetylase 10 promotes autophagy-mediated cell survival. Proc Natl Acad Sci USA 110(28):E2592-601. https://doi.org/10.1073/pnas.1300113110

Pajtler KW, Mahlow E, Odersky A et al (2014) Neuroblastoma in dialog with its stroma: NTRK1 is a regulator of cellular crosstalk with Schwann cells. Oncotarget 5(22):11180-11192. https:// doi.org/10.18632/oncotarget.2611

Pang X, He G, Luo C, Wang Y, Zhang B (2016) Knockdown of Rad9A enhanced DNA damage induced by trichostatin A in esophageal cancer cells. Tumor Biol 37(1):9639-9670. https:// doi.org/10.1007/s13277-015-3879-z

Park JH, Kim SH, Choi MC et al (2008) Class II histone deacetylases play pivotal roles in heat shock protein 90 -mediated proteasomal degradation of vascular endothelial growth factor receptors. Biochem Biophys Res Commun 368(2):318-322. https://doi. org/10.1016/j.bbrc.2008.01.056

Pinto NR, Applebaum MA, Volchenboum SL et al (2015) Advances in risk classification and treatment strategies for neuroblastoma. J Clin Oncol 33(27):3008-3017. https://doi.org/10.1200/ JCO.2014.59.4648

Radhakrishnan R, Li Y, Xiang S et al (2015) Histone deacetylase 10 regulates DNA mismatch repair and may involve the deacetylation of MutS homolog 2. J Biol Chem 290(37):22795-22804. https:// doi.org/10.1074/jbc.M114.612945

Rettig I, Koeneke E, Trippel F et al (2015) Selective inhibition of HDAC8 decreases neuroblastoma growth in vitro and in vivo and enhances retinoic acid-mediated differentiation. Cell Death Dis 6:e1657. https://doi.org/10.1038/cddis.2015.24

PDQ Pediatric Treatment Editorial Board, PDQ Cancer Information Summaries [Internet]. Bethesda (MD): National Cancer Institute (US) (2002-2017) Neuroblastoma Treatment (PDQ®): Health Professional Version

Robers MB, Dart ML, Woodroofe CC et al (2015) Target engagement and drug residence time can be observed in living cells with 
BRET. Nat Commun 6:10091. https://doi.org/10.1038/ncomm s10091

Robert C, Nagaria PK, Pawar N et al (2016) Histone deacetylase inhibitors decrease NHEJ both by acetylation of repair factors and trapping of PARP1 at DNA double-strand breaks in chromatin. Leuk Res 45:14-23. https://doi.org/10.1016/j.leukres.2016.03.007

Rogakou EP, Nieves-Neira W, Boon C, Pommier Y, Bonner WM (2000) Initiation of DNA fragmentation during apoptosis induces phosphorylation of H2AX histone at serine 139. J Biol Chem 275(13):9390-9395

Santo L, Hideshima T, Kung AL et al (2012) Preclinical activity, pharmacodynamic, and pharmacokinetic properties of a selective HDAC6 inhibitor, ACY-1215, in combination with bortezomib in multiple myeloma. Blood 119(11):2579-2589. https://doi. org/10.1182/blood-2011-10-387365

Schneider CA, Rasband WS, Eliceiri KW (2012) NIH Image to ImageJ: 25 years of image analysis. Nat Methods 9(7):671-675

Schramm A, Schowe B, Fielitz K et al (2012) Exon-level expression analyses identify MYCN and NTRK1 as major determinants of alternative exon usage and robustly predict primary neuroblastoma outcome. Br J Cancer 107(8):1409-1417. https://doi. org/10.1038/bjc.2012.391

Shi Y, Dong M, Hong X et al (2015) Results from a multicenter, openlabel, pivotal phase II study of chidamide in relapsed or refractory peripheral T-cell lymphoma. Ann Oncol 26(8):1766-1771. https ://doi.org/10.1093/annonc/mdv237

Uhlmann F (2016) SMC complexes: from DNA to chromosomes. Nat Rev Mol Cell Biol 17(7):399-412. https://doi.org/10.1038/ nrm. 2016.30

Vashishta A, Hetman M (2014) Inhibitors of histone deacetylases enhance neurotoxicity of DNA damage. Neuromol Med 16(4):727-741. https://doi.org/10.1007/s12017-014-8322-x

Vogl DT, Raje N, Jagannath S et al (2017) Ricolinostat, the first selective histone deacetylase 6 inhibitor, in combination with bortezomib and dexamethasone for relapsed or refractory multiple myeloma. Clin Cancer Res Off J Am Assoc Cancer Res 23(13):3307-3315. https://doi.org/10.1158/1078-0432. CCR-16-2526

Wang L, Xiang S, Williams KA et al (2012) Depletion of HDAC6 enhances cisplatin-induced DNA damage and apoptosis in nonsmall cell lung cancer cells. PLoS One 7(9):e44265. https://doi. org/10.1371/journal.pone.0044265

Ward E, DeSantis C, Robbins A, Kohler B, Jemal A (2014) Childhood and adolescent cancer statistics, 2014. CA Cancer J Clin 64(2):83-103. https://doi.org/10.3322/caac.21219

Watrin E, Peters JM (2009) The cohesin complex is required for the DNA damage-induced G2/M checkpoint in mammalian cells. EMBO J 28(17):2625-2635. https://doi.org/10.1038/emboj .2009 .202

Witt O, Monkemeyer S, Ronndahl G et al (2003) Induction of fetal hemoglobin expression by the histone deacetylase inhibitor apicidin. Blood 101(5):2001-2007. https://doi.org/10.1182/blood $-2002-08-2617$

Witt O, Deubzer HE, Lodrini M, Milde T, Oehme I (2009a) Targeting histone deacetylases in neuroblastoma. Curr Pharm Des 15(4):436-447

Witt O, Deubzer HE, Milde T, Oehme I (2009b) HDAC family: what are the cancer relevant targets? Cancer Lett 277(1):8-21. https:// doi.org/10.1016/j.canlet.2008.08.016

Yang XJ, Seto E (2008) The Rpd3/Hda1 family of lysine deacetylases: from bacteria and yeast to mice and men. Nat Rev Mol Cell Biol 9(3):206-218. https://doi.org/10.1038/nrm2346

Yee AJ, Bensinger WI, Supko JG et al (2016) Ricolinostat plus lenalidomide, and dexamethasone in relapsed or refractory multiple myeloma: a multicentre phase $1 \mathrm{~b}$ trial. Lancet Oncol 17(11):15691578. https://doi.org/10.1016/S1470-2045(16)30375-8 